\title{
Noradrenaline-Induced Relaxation of Urinary Bladder Smooth Muscle Is Primarily Triggered through the $\boldsymbol{\beta}_{\mathbf{3}}$-Adrenoceptor in Rats
}

\author{
Keisuke Obara, ${ }^{a}$ Serena Suzuki, ${ }^{a}$ Hiroko Shibata,${ }^{a}$ Naoki Yoneyama, ${ }^{a}$ Shoko Hamamatsu, ${ }^{a}$ \\ Fumiko Yamaki, ${ }^{a}$ Koji Higai, ${ }^{b}$ and Yoshio Tanaka*, ${ }^{* a}$ \\ ${ }^{a}$ Department of Chemical Pharmacology, Faculty of Pharmaceutical Sciences, Toho University; 2-2-1 Miyama, \\ Funabashi, Chiba 274-8510, Japan: and ${ }^{b}$ Laboratory of Medical Biochemistry, Faculty of Pharmaceutical Sciences, \\ Toho University; 2-2-1 Miyama, Funabashi, Chiba 274-8510, Japan. \\ Received November 18, 2018; accepted January 25, 2019
}

\begin{abstract}
$\beta$-Adrenoceptors are subclassified into 3 subtypes $\left(\beta_{1}-\beta_{3}\right)$. Among these, $\beta_{3}$-adrenoceptors are present in various types of smooth muscle and are believed to play a role in relaxation responses of these muscles. $\beta_{3}$-Adrenoceptors are also present in urinary bladder smooth muscle (UBSM), although their expression varies depending on the animal species. To date, there has been little information available about the endogenous ligand that stimulates $\beta_{3}$-adrenoceptors to produce relaxation responses in UBSM. In this study, to determine whether noradrenaline is a ligand of UBSM $\beta_{3}$-adrenoceptors, noradrenaline-induced relaxation was analyzed pharmacologically using rat UBSM. We also assessed whether noradrenaline metabolites were ligands in UBSM. In isolated rat urinary bladder tissues, mRNAs for $\beta_{1^{-}}, \boldsymbol{\beta}_{2^{-}}$, and $\boldsymbol{\beta}_{3^{-}}$-adrenoceptors were detected using RT-PCR. In UBSM preparations contracted with methacholine $\left(3 \times 10^{-5} \mathrm{M}\right)$, noradrenalineinduced relaxation was not inhibited by the following antagonists: atenolol $\left(10^{-6} \mathrm{M}\right.$; selective $\beta_{1}$-adrenoceptor antagonist), ICI-118,551 $\left(3 \times 10^{-8} \mathrm{M}\right.$; selective $\beta_{2}$-adrenoceptor antagonist), propranolol $\left(10^{-7} \mathrm{M}\right.$; non-selective $\beta$-adrenoceptor antagonist), and bupranolol $\left(10^{-7} \mathrm{M}\right.$; non-selective $\beta$-adrenoceptor antagonist). In the presence of propranolol $\left(10^{-6} \mathrm{M}\right)$, noradrenaline-induced relaxation was competitively inhibited by bupranolol $\left(3 \times 10^{-7}-3 \times 10^{-6} \mathrm{M}\right)$ or SR59230A $\left(10^{-7}-10^{-6} \mathrm{M}\right.$; selective $\beta_{3}$-adrenoceptor antagonist), with their $\mathrm{p} A_{2}$ values calculated to be 6.64 and 7.27 , respectively. None of the six noradrenaline metabolites produced significant relaxation of methacholine-contracted UBSM. These findings suggest that noradrenaline, but not its metabolites, is a ligand for $\beta_{3}$-adrenoceptors to produce relaxation responses of UBSM in rats.
\end{abstract}

Key words rat urinary bladder smooth muscle; noradrenaline; $\beta$-adrenoceptor

\section{INTRODUCTION}

The urinary bladder (UB) is an organ that stores urine and discharges it outside the body. These physiological functions are controlled by the relaxation and contraction responses of UB smooth muscle (UBSM), and both responses are affected strongly by autonomic nerves. In particular, urine discharge is associated with UBSM contraction. This contraction is principally triggered by acetylcholine that is released from parasympathetic nerve endings, the activity of which predominates in the micturition phase. In contrast, urine storage (retention) is associated with UBSM relaxation. This relaxation response is generally considered to be triggered by noradrenaline that is released from sympathetic nerve endings, the activity of which predominates in the UB filling phase ${ }^{1-3)}$ However, how sympathetic nerves contribute to the relaxation of UBSM and urine storage is not completely understood.

If noradrenaline is a key molecule to trigger UBSM relaxation, it is reasonable to postulate that it would target $\beta$-adrenoceptors in UBSM, as it does in other smooth muscles. $\beta$-Adrenoceptors are classified into 3 subtypes $\left(\beta_{1}-\beta_{3}\right),{ }^{4}$ and UBSM subtype expression is species-dependent. ${ }^{5}$ In humans, the main $\beta$-adrenoceptor subtype in UBSM has been identified as $\beta_{3}$ at the mRNA level. ${ }^{5,6)}$ In addition, a selective $\beta_{3}$ adrenoceptor agonist, mirabegron, has been reported to induce UBSM relaxation and improve overactive bladder (OAB) symptoms by increasing bladder capacity. ${ }^{7-9)}$ These findings suggest that $\beta_{3}$-adrenoceptors play a significant role in the regulation of the UBSM relaxation response and, thus, urine storage. However, whether noradrenaline acts as an endogenous ligand for the $\beta_{3}$-adrenoceptor to induce UBSM relaxation has not been convincingly established. This is because almost all pharmacological studies on UBSM $\beta$-adrenoceptors were designed using synthetic $\beta$-adrenoceptor agonists (isoprenaline or selective $\beta_{3}$-adrenoceptor agonists), but not endogenous catecholamines such as noradrenaline.

The purpose of this study was to investigate whether noradrenaline is a ligand for the $\beta_{3}$-adrenoceptor using rat UBSM tissue. This tissue expresses all subtypes of $\beta$-adrenoceptors, ${ }^{10,11)}$ allowing the determination of whether noradrenaline can stimulate $\beta_{1}$ and $\beta_{2}$ subtypes in addition to $\beta_{3}$. In this study, we also examined six metabolites of noradrenaline in order to verify whether they can induce UBSM relaxation via stimulation of $\beta_{3}$-adrenoceptors.

\section{MATERIALS AND METHODS}

Drugs The followings drugs were used: ( \pm )-atenolol, desipramine hydrochloride, 3,4-dihydroxymandelic acid (DOMA), DL-3,4-dihydroxyphenylglycol (DHPG), 3,5-dinitrocatechol, DL-4-hydroxy-3-methoxymandelic acid (VMA), 4-hydroxy-3-methoxyphenyl glycol (MHPG) hemipiperazinium salt, 4-hydroxy-3-methoxyphenylglycol sulfate (MHPGS) potassium salt, indomethacin, ICI-118,551 hydrochloride, (-)-isoproterenol (ISO) hydrochloride, DL-normetanephrine (NMN) hydrochloride, $N$-methyl- $N$-propargyl-3-(2,4-dichlo- 
rophenoxy)propylamine (clorgiline) hydrochloride, DL-propranolol hydrochloride, SR 59230A (all from Sigma-Aldrich Co., St. Louis, MO, U.S.A.); ( \pm )-phentolamine mesylate (Novartis Pharma, Basel, Switzerland); acetyl- $\beta$-methylcholine (methacholine) chloride, $(R)-(-)$-norepinephrine (noradrenaline) hydrogen tartrate monohydrate (both from Wako Pure Chemical Industries, Ltd., Osaka, Japan); and (土)-bupranolol hydrochloride (Kaken Pharmaceutical Co., Ltd., Tokyo, Japan). All other chemicals were commercially available and reagent grade.

Atenolol was dissolved in $0.1 \mathrm{~N}$ hydrochloric acid $(\mathrm{HCl})$ as a stock solution at $2 \times 10^{-2} \mathrm{M}$ and diluted with distilled water. Indomethacin was dissolved in pure ethanol as a stock solution at $10^{-2}$ M. 3,5-Dinitrocatechol was dissolved in dimethyl sulfoxide (DMSO) as a stock solution at $4 \times 10^{-3} \mathrm{M}$ and diluted with distilled water. SR 59230A was dissolved in DMSO as a stock solution at $2 \times 10^{-2} \mathrm{M}$ and diluted with distilled water. All other drugs were prepared as aqueous stock solutions and diluted with distilled water.

Animals Male Wistar rats (8-10 weeks old; weight 165-265 g, Sankyo Labo Service Corporation, Tokyo, Japan) were housed under controlled conditions $\left(21-22^{\circ} \mathrm{C}\right.$, relative air humidity $50 \pm 5 \%$, fixed $12 \mathrm{~h}$ light-dark cycle (08:00-20:00)) with food and water available ad libitum. This study was approved by the Toho University Animal Care and User Committee (approval number: 16-52-294, accredited on May 16, 2016; approval number: 17-53-294, accredited on May 17, 2017) and was conducted in accordance with the User's Guideline to the Laboratory Animal Center of Faculty of Pharmaceutical Sciences, Toho University.

RT-PCR Analysis of $\beta$-Adrenoceptor Subtype mRNA Expression The rats were anaesthetized with isoflurane (inhalation) and euthanized by exsanguination from a carotid artery. The UB, atrium (both right and left atria), and ileum were immediately removed and placed in normal Tyrode's solution of the following composition $(\mathrm{mM})$ : NaCl, $158.3 ; \mathrm{KCl}$, 4.0; $\mathrm{CaCl}_{2}, 2.0 ; \mathrm{MgCl}_{2}, 1.05 ; \mathrm{NaH}_{2} \mathrm{PO}_{4}, 0.42 ; \mathrm{NaHCO}_{3}, 10.0$; and glucose, 5.6. All tissues were stripped of surrounding adipose and connective tissue, and the bladder trigone from the UB. After washing out debris, and inserting an acrylic rod into the lumen of the ileum, the longitudinal ileal smooth muscle was isolated using tweezers and a cotton swab. The preparations were frozen in liquid nitrogen after removing moisture with filter paper. These frozen preparations were pulverized using a frozen cell crusher apparatus (Cryo-Press ${ }^{\mathrm{TM}}$; Microtec Co., Ltd., Funabashi, Chiba, Japan).

Total RNA from the resulting powders was extracted using RNAiso Plus ${ }^{\mathrm{TM}}$ (TaKaRa Bio Inc., Shiga, Japan) according to the manufacturer's protocol. First-strand cDNA was synthesized by reverse transcription with $0.5 \mu \mathrm{g}$ total RNA per $10 \mu \mathrm{L}$ reaction mixture using ReverTra Ace ${ }^{\circledR}$ qPCR RT Master Mix with gDNA Remover (TOYOBO Co., Ltd., Osaka, Japan). PCR was performed using the GoTaq ${ }^{\circledR}$ Green Master Mix (Promega Corp., Madison, WI, U.S.A.) with $0.5 \mu \mathrm{L}$ cDNA solution per $10 \mu \mathrm{L}$ reaction mixture in a TaKaRa PCR Thermal Cycler Dice ${ }^{\circledR}$ Touch (TaKaRa Bio Inc.). The specific oligonucleotide primers for $\beta_{1}$-adrenoceptors (forward, 5'-GATCTGGTCATGGGACTGCT-3' and reverse, 5'-AG C ACT TGGGGT CGT TGT AG-3'), $\beta_{2}$-adrenoceptors (forward, 5'-ACC AAG AAT AAGGCC CGAGT-3' and reverse, 5'-GT C TTG AGG GCT TTG TGC TC-3'), $\beta_{3}$-adrenoceptors (forward, 5'-TGC TCG AGT GTT CGT CGT AG-3' and reverse, 5'-GAA
GGC AGA GTT GGC ATA GC-3'), and $\beta$-actin (forward, $5^{\prime}$-ATG GTGGGT ATGGGTCAGAA-3' and reverse, 5'-ACCCTC ATAGATGGGCACAG-3') were synthesized at Eurofins Genomics (Tokyo, Japan). The PCR samples were heated for $2 \mathrm{~min}$ at $95^{\circ} \mathrm{C}$, and then amplified by 35 cycles at $95^{\circ} \mathrm{C}$ for $20 \mathrm{~s}, 60^{\circ} \mathrm{C}$ for $5 \mathrm{~s}$, and $72^{\circ} \mathrm{C}$ for $30 \mathrm{~s}$ ( $\beta$-adrenoceptors) or by 25 cycles at $95^{\circ} \mathrm{C}$ for $20 \mathrm{~s}, 60^{\circ} \mathrm{C}$ for $5 \mathrm{~s}$, and $72^{\circ} \mathrm{C}$ for $30 \mathrm{~s}$ ( $\beta$-actin), followed by a 5 -min extension at $72^{\circ} \mathrm{C}$. The PCR products were separated via $1.5 \%$ agarose gel (containing ethidium bromide) electrophoresis and visualized under UV illumination.

Preparation of UB Strips and Recording of Isotonic Tension Changes The isolated rat UB, after removing the surrounding adipose tissue, connective tissue, and bladder trigone, was opened with a longitudinal incision and UB strips (approximately $2 \mathrm{~mm}$ in width $\times 25 \mathrm{~mm}$ in length) were prepared in normal Tyrode's solution. The UB strips were mounted under an optimal resting tension of $0.5 \mathrm{~g}$ in a $20-\mathrm{mL}$ organ bath containing normal Tyrode's solution, aerated with $95 \%$ $\mathrm{O}_{2}$ and $5 \% \mathrm{CO}_{2}$, and maintained at $32 \pm 1{ }^{\circ} \mathrm{C}$. Tension changes were recorded isotonically via a kymograph and lever. The UB preparations were equilibrated for $60 \mathrm{~min}$ prior to the first methacholine-induced contraction, during which time the normal Tyrode's solution was replaced every $20 \mathrm{~min}$ with fresh solution. After the initial 60-min incubation, the UB preparation was contracted with methacholine $\left(3 \times 10^{-5} \mathrm{M}\right)$. When the contraction reached steady-state, the preparation was relaxed by applying isoprenaline. This procedure was performed twice before starting the experiment (performed 3 times in total). All experiments were carried out in the presence of indomethacin $\left(3 \times 10^{-6} \mathrm{M}\right)$ to prevent any possible effects of endogenous prostaglandins.

Evaluation of Effects of $\boldsymbol{\beta}$-Adrenoceptor Antagonists on Noradrenaline-Induced Relaxation After conducting the preliminary procedures described in the previous section, the UB preparations were treated with methacholine $\left(3 \times 10^{-5} \mathrm{M}\right)$. When the contraction reached a steady-state level, noradrenaline was cumulatively applied to the bath solution in order to obtain a concentration-response curve. After the UB preparation had been fully recovered by washing with fresh bath solution, the preparation was again treated with methacholine $\left(3 \times 10^{-5} \mathrm{M}\right)$ in the presence of the indicated $\beta$-adrenoceptor antagonists; when the methacholine-induced contraction reached steady-state, noradrenaline was cumulatively applied in order to obtain a concentration-response curve. The tested $\beta$-adrenoceptor antagonists were atenolol $\left(10^{-6} \mathrm{M}\right)$, ICI-118,551 $\left(3 \times 10^{-8} \mathrm{M}\right)$, propranolol $\left(10^{-7}-10^{-6} \mathrm{M}\right)$, bupranolol $\left(10^{-7}-3 \times 10^{-6} \mathrm{M}\right)$, and SR 59230A $\left(10^{-7}-10^{-6} \mathrm{M}\right)$. When bupranolol $\left(3 \times 10^{-7}-3 \times 10^{-6} \mathrm{M}\right)$ or SR 59230A $\left(10^{-7}-10^{-6} \mathrm{M}\right)$ was administered, the experiment was performed in the presence of propranolol $\left(10^{-6} \mathrm{M}\right)$ according to previous studies. ${ }^{12,13)}$

This series of experiments was carried out in the presence of desipramine $\left(3 \times 10^{-7} \mathrm{M}\right)$ as an uptake- 1 inhibitor, NMN $\left(10^{-6} \mathrm{M}\right)$ as an uptake-2 inhibitor, and phentolamine $\left(10^{-6} \mathrm{M}\right)$ as a non-selective $\alpha$-adrenoceptor antagonist to prevent possible effects of noradrenaline reuptake or $\alpha$-adrenoceptors. These drugs were administered 20 min before methacholine.

Evaluation of Effects of Noradrenaline Metabolites on Methacholine-Induced Contraction After conducting the preliminary procedures described in "Preparation of UB Strips and Recording of Isotonic Tension Changes," the UB 
preparations were treated with methacholine $\left(3 \times 10^{-5} \mathrm{M}\right)$. When the contraction reached a steady-state level, noradrenaline or the indicated noradrenaline metabolites $\left(10^{-4} \mathrm{M}\right.$ each $)$ was applied to the bath solution. Ten minutes after the administration, isoprenaline $\left(10^{-4} \mathrm{M}\right)$ was applied to confirm that the UB preparation was sufficiently relaxed.

This series of experiments was carried out in the presence of clorgiline $\left(10^{-5} \mathrm{M}\right)$ as a monoamine oxidase $\mathrm{A}\left(\mathrm{MAO}_{\mathrm{A}}\right)$ inhibitor, 3,5-dinitrocatechol $\left(2 \times 10^{-6} \mathrm{M}\right)$ as a catechol- $O$-methyltransferase (COMT) inhibitor, and phentolamine $\left(10^{-6} \mathrm{M}\right)$ to prevent any possible effects of metabolism of noradrenaline or $\alpha$-adrenoceptors. These drugs were administered $20 \mathrm{~min}$ before methacholine.

Data Analysis The extent of relaxation induced by noradrenaline and the six noradrenaline metabolites was calculated relative to the tone level before the application of $3 \times 10^{-5} \mathrm{M}$ methacholine (100\% relaxation), and to the steadystate tone level prior to the application of each relaxant $(0 \%$ relaxation).

The potencies of noradrenaline were calculated as $\mathrm{p} D_{2}$ $\left(\mathrm{pEC}_{50}\right)$ values (the negative logarithm of the effective agonist concentration producing a response that is $50 \%$ of the maximum response). The data were plotted as a function of noradrenaline concentration and fitted to the equation:

$$
E=\mathrm{E}_{\max } \times A^{n_{\mathrm{H}}} /\left(\mathrm{EC}_{50}^{n_{\mathrm{H}}}+A^{n_{\mathrm{H}}}\right)
$$

where $E$ is the \% relaxation at a given concentration, $\mathrm{E}_{\max }$ is the maximum response, $A$ is the noradrenaline concentration, $n_{\mathrm{H}}$ is the Hill coefficient, and $\mathrm{EC}_{50}$ is the agonist concentration producing a $50 \%$ response. Curve-fitting was carried out using GraphPad Prism ${ }^{\mathrm{TM}}$ (Version 6.07; GraphPad Software, Inc., San Diego, CA, U.S.A.).

The $\beta$-adrenoceptor antagonist potencies are expressed as $\mathrm{p} A_{2}$ values, which were calculated according to the method originally reported by Arunlakshana and Schild. ${ }^{14)}$

Data are expressed as means \pm standard error of the mean (S.E.M.) or means with $95 \%$ confidence intervals (95\% CIs) and $n$ refers to the number of experiments. The significance of the differences between mean values was evaluated by two-way ANOVA or paired $t$-tests using GraphPad Prism ${ }^{\mathrm{TM}}$. A $p$-value less than 0.05 was considered statistically significant.

\section{RESULTS}

Expression of mRNAs for $\boldsymbol{\beta}$-Adrenoceptor Subtypes in Rat UB Preparations Figure 1 shows representative images of agarose gels for $\beta_{1^{-}}, \beta_{2^{-}}$, and $\beta_{3}$-adrenoceptor PCR products in rat UB, atrium (both right and left atria) (A), and ileal longitudinal smooth muscle (I), with the expected PCR products of 337, 386, and 352 base pairs, respectively. In both the UB and ileal longitudinal smooth muscle, mRNAs for all 3 $\beta$-adrenoceptors $\left(\beta_{1^{-}}, \beta_{2^{-}}\right.$, and $\left.\beta_{3^{-}}\right)$were detected. In contrast, in the atrium, $\beta_{1}$ - and $\beta_{2}$-adrenoceptor mRNAs were clearly detected, but that of $\beta_{3}$-adrenoceptor was absent or barely detected. The PCR product for $\beta$-actin, as an internal standard, was detected in all 3 preparations; this had the expected size of 375 base pairs. No bands were observed in the absence of reverse transcription $(\mathrm{RT}(-))$.

Effects of Various Antagonists for $\beta$-Adrenoceptors on Noradrenaline-Induced Relaxation Figure 2A shows the effects of repeated noradrenaline administration on its concentration-relaxation curves in rat UBSM. The response curves of noradrenaline did not change in both the first and second applications; this was evidenced by the lack of statistically significant differences in both $\mathrm{p} D_{2}(5.85 \pm 0.08$ for first and $5.83 \pm 0.05$ for second, $n=8$ each, $p>0.05)$ and $\mathrm{E}_{\max }$ $(52.4 \pm 4.4 \%$ for first and $50.3 \pm 3.0 \%$ for second, $n=8$ each, $p>0.05)$ values between the first and second applications.

Figures 2B-F show the effects of various types of $\beta$-adrenoceptor antagonists on noradrenaline-induced relaxation. The tested $\beta$-adrenoceptor antagonists were: atenolol (a selective $\beta_{1}$-adrenoceptor antagonist, $10^{-6} \mathrm{M}$ ) (Fig. 2B), ICI-118,551 (a selective $\beta_{2}$-adrenoceptor antagonist, $3 \times 10^{-8} \mathrm{M}$ ) (Fig. $2 \mathrm{C}$ ), propranolol (a nonselective $\beta$-adrenoceptor antagonist, $10^{-7} \mathrm{M}, 10^{-6} \mathrm{M}$ ) (Figs. 2D, E, respectively), and bupranolol (a nonselective $\beta$-adrenoceptor antagonist, $10^{-7} \mathrm{M}$ ) (Fig. $2 \mathrm{~F}$ ). Noradrenaline-induced relaxation was not affected by atenolol, ICI-118,551, $10^{-7} \mathrm{M}$ propranolol, or bupranolol $\left(10^{-7} \mathrm{M}\right)$. However, the noradrenaline-induced relaxation curve was shifted rightward by approximately 2-fold by $10^{-6} \mathrm{M}$ propranolol (Fig. 2E).

Effects of Bupranolol and SR 59230A on NoradrenalineInduced Relaxation Figure 3A shows the effects of repeated noradrenaline administration on its concentration-relaxation curves in rat UBSM in the presence of propranolol $\left(10^{-6} \mathrm{M}\right)$. The response curves of noradrenaline did not change in both the first and second applications; this was demonstrated by the absence of statistically significant differences in both $\mathrm{p} D_{2}$ $(5.36 \pm 0.04$ for first and $5.32 \pm 0.03$ for second, $n=12$ each, $p>0.05)$ and $\mathrm{E}_{\max }(45.6 \pm 2.0 \%$ for first and $43.6 \pm 1.9 \%$ for second, $n=12$ each, $p>0.05)$ values between the first and second applications.

Figures 3B-D show the effects of bupranolol on noradrenaline-induced relaxation in the presence of propranolol $\left(10^{-6} \mathrm{M}\right)$. The noradrenaline-induced relaxation was inhibited by bupranolol $\left(3 \times 10^{-7}-3 \times 10^{-6} \mathrm{M}\right)$ in a concentration-dependent manner, shifting the corresponding concentrationresponse curve rightward (Figs. 3B-D). Figure 3E shows the Schild plot of bupranolol against noradrenaline based on the results of Figs. 3B-D. Schild regression analysis generated a straight line with a slope of 0.92 , which was not significantly different from unity (95\% CIs: $0.52-1.31, n=13$ ) (Fig. 3E). This indicates that noradrenaline-induced relaxation was antagonized competitively by bupranolol $\left(3 \times 10^{-7}-3 \times 10^{-6} \mathrm{M}\right)$

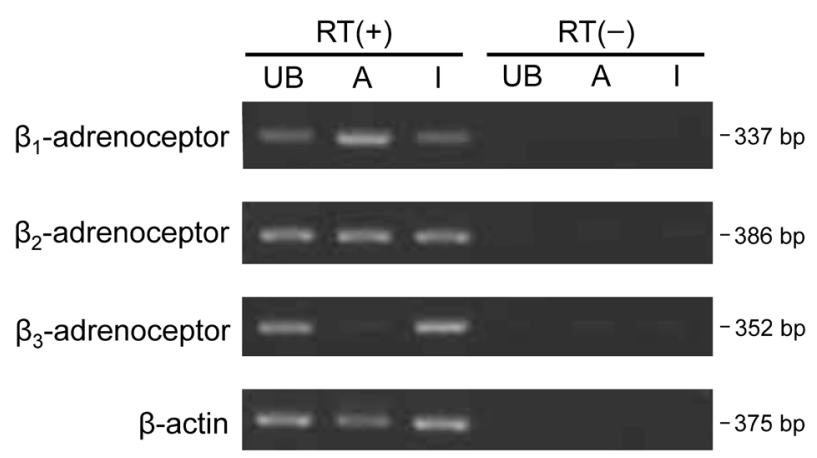

Fig. 1. Representative Images of Agarose Gels Showing Expression of the Indicated mRNAs in Rat Urinary Bladder (UB), Atrium (both Right and Left Atria) (A), and Ileal Longitudinal Smooth Muscle (I)

The PCR products for $\beta_{1^{-}}, \beta_{2^{-}}$, and $\beta_{3}$-adrenoceptors, and $\beta$-actin are 337, 386, 352 , and $375 \mathrm{bp}$, respectively. RT(+): reverse transcription, RT(-): no reverse transcription. These results are representative of four experiments. 

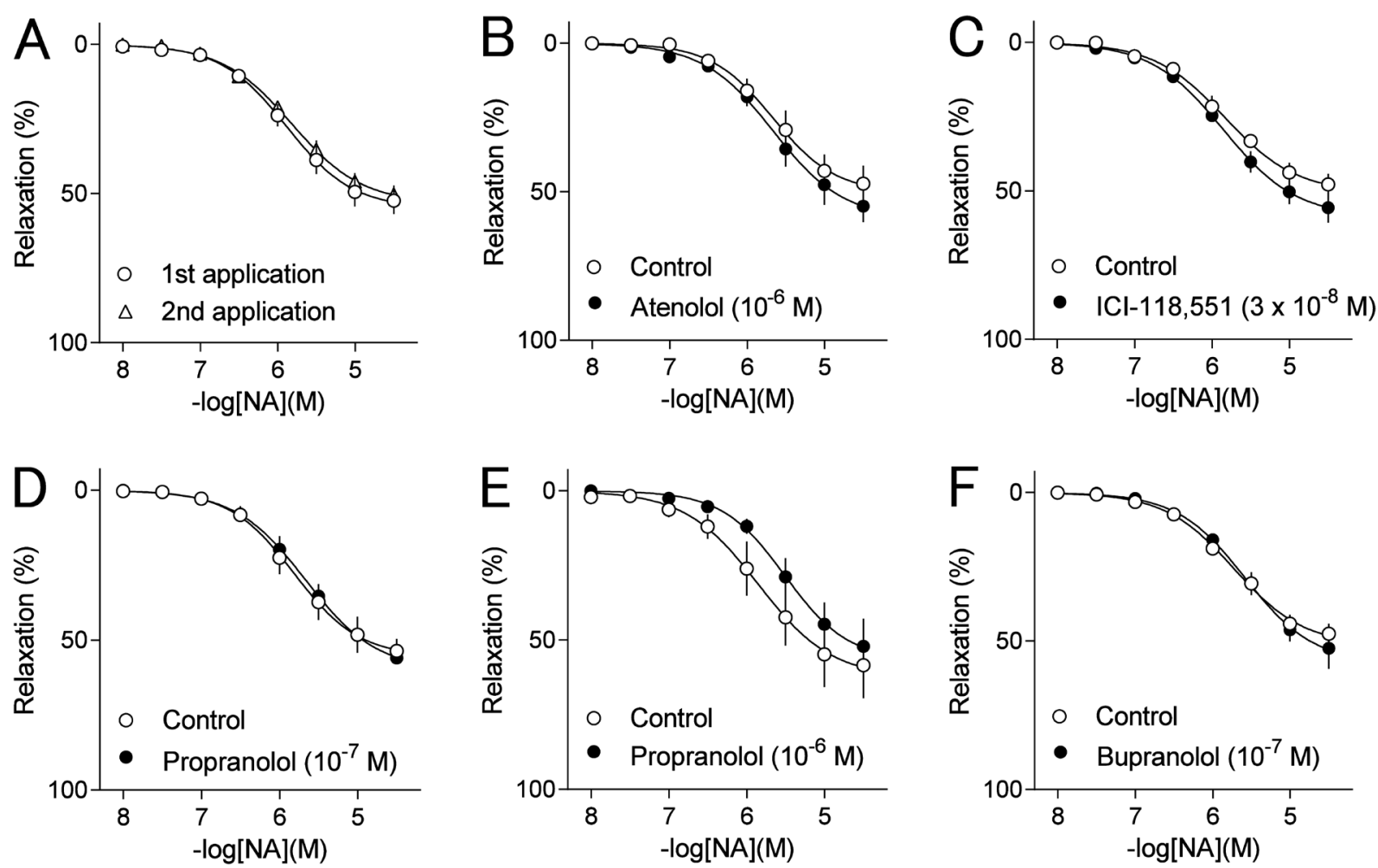

Fig. 2. Effect of Various $\beta$-Adrenoceptor Antagonists on Noradrenaline-Induced Relaxation in Rat Urinary Bladder Smooth Muscle (UBSM)

A: Reproducibility of the concentration-response curves for noradrenaline-induced relaxation between successive applications. B-F: Effects of atenolol (10 ${ }^{-6} \mathrm{M}$; B), ICI-118,551 $\left(3 \times 10^{-8} \mathrm{M} ; \mathrm{C}\right)$, propranolol $\left(10^{-7} \mathrm{M} ; \mathrm{D}, 10^{-6} \mathrm{M} ; \mathrm{E}\right)$, and bupranolol $\left(10^{-7} \mathrm{M} ; \mathrm{F}\right)$ on the concentration-response curves for noradrenaline-induced relaxation. Data are presented as means \pm S.E.M., $n=8$ (part A), and $n=4$ (B-F).

in the presence of $10^{-6} \mathrm{M}$ propranolol. The $\mathrm{p} A_{2}$ value of bupranolol was calculated to be 6.64 (95\% CIs: $6.40-7.17, n=13)$

Figure 4 shows the effects of SR 59230A on noradrenalineinduced relaxation in the presence of propranolol $\left(10^{-6} \mathrm{M}\right)$. The noradrenaline-induced relaxation was inhibited by SR $59230 \mathrm{~A}\left(10^{-7}-10^{-6} \mathrm{M}\right)$ in a concentration-dependent manner, shifting the corresponding concentration-response curve to the right (Figs. 4A-C). Figure 4D shows the Schild plot of SR 59230A against noradrenaline based on the results of Figs. 4A-C. Schild regression analysis produced a straight line with a slope of 0.95 , which was not significantly different from unity (95\% CIs: $0.40-1.50, n=12$ ) (Fig. 4D). This indicates that noradrenaline-induced relaxation was antagonized competitively by SR 59230A $\left(10^{-7}-10^{-6} \mathrm{M}\right)$ in the presence of $10^{-6} \mathrm{M}$ propranolol. The $\mathrm{p} A_{2}$ value of SR $59230 \mathrm{~A}$ was calculated to be 7.27 (95\% CIs: $6.92-8.38, n=12$ )

Effects of Noradrenaline Metabolites on Methacholine $\left(3 \times \mathbf{1 0}^{-5} \mathbf{M}\right)$-Induced Contraction Noradrenaline is metabolized by $\mathrm{MAO}_{\mathrm{A}}$ and COMT. ${ }^{15)}$ In this series of experiments, we investigated the effects of six metabolites of noradrenaline (i.e., NMN, DOMA, DHPG, VMA, MHPG, and MHPG-S) in order to determine whether these metabolites can induce a UBSM relaxation response via $\beta_{3}$-adrenoceptor stimulation. In the presence of clorgiline (a $\mathrm{MAO}_{\mathrm{A}}$ inhibitor, $10^{-5} \mathrm{M}$ ) and 3,5-dinitrocatechol (a COMT inhibitor, $2 \times 10^{-6} \mathrm{M}$ ), noradrenaline $\left(10^{-4} \mathrm{M}\right)$ elicited a relaxation response as shown in Fig. $5 \mathrm{~A}$ (white column). Noradrenaline $\left(10^{-4} \mathrm{M}\right)$-induced relaxation was not further augmented by isoprenaline $\left(10^{-4} \mathrm{M}\right)$ (Fig. 5A, black column).

In contrast, none of the 6 metabolites (NMN, DOMA, DHPG, VMA, MHPG, or MHPG-S, $10^{-4} \mathrm{M}$ each) induced a relaxation response (Figs. 5B-G). However, NMN $\left(10^{-4} \mathrm{M}\right)$ augmented the methacholine-induced $\left(3 \times 10^{-5} \mathrm{M}\right)$ contraction of the UBSM preparation by approximately 10\% (Fig. 5B).

\section{DISCUSSION}

In this study, we investigated whether noradrenaline could be a ligand for the $\beta_{3}$-adrenoceptor by pharmacological identification of the $\beta$-adrenoceptor subtypes that trigger relaxation responses to noradrenaline in rat UBSM. We also examined 6 metabolites of noradrenaline (i.e., NMN, DOMA, DHPG, VMA, MHPG, and MHPG-S) in order to determine whether they are able to induce UBSM relaxation responses via $\beta_{3}$ adrenoceptor stimulation. Our pharmacological studies indicated that the predominant $\beta$-adrenoceptor subtype to mediate noradrenaline-induced relaxation is $\beta_{3}$, and thus, noradrenaline was suggested to be a ligand for the $\beta_{3}$-adrenoceptor in rat UBSM. In contrast, since none of the noradrenaline metabolites showed a relaxation response, these metabolites are not ligands for the $\beta_{3}$-adrenoceptor.

First, we will discuss the possible $\beta$-adrenoceptor subtypes in rat UBSM. In the RT-PCR experiment, we detected mRNA expression of all $3 \beta$-adrenoceptor subtypes $\left(\beta_{1}, \beta_{2}\right.$, and $\beta_{3}$ ) (Fig. 1). This result supports the findings in previous reports. ${ }^{10,11)}$ In those reports, in rat UBSM, all three $\beta$-adrenoceptor subtypes were suggested to have functional significance, as supported by the following pharmacological findings: 1) rat UBSM was relaxed substantially by selective agonists for each subtype (i.e., T-0509 for $\beta_{1}$, terbutaline for $\beta_{2}$, and BRL 37344A for $\left.\beta_{3}\right)^{16)}$; and 2) a subtype non-selective agonist for $\beta$-adrenoceptors (isoprenaline) was significantly 


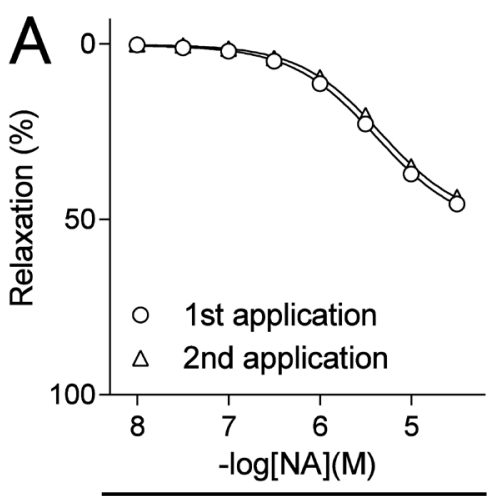

Propranolol $\left(10^{-6} \mathrm{M}\right)$

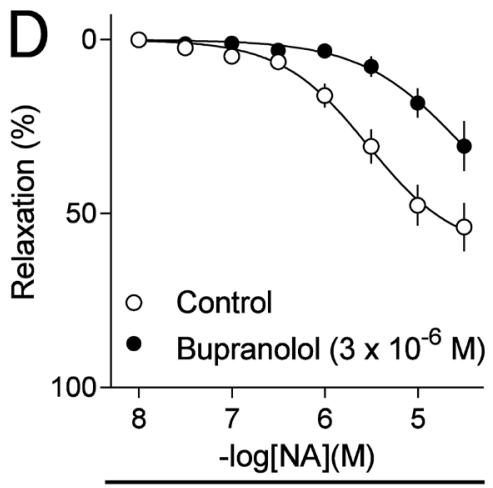

Propranolol $\left(10^{-6} \mathrm{M}\right)$
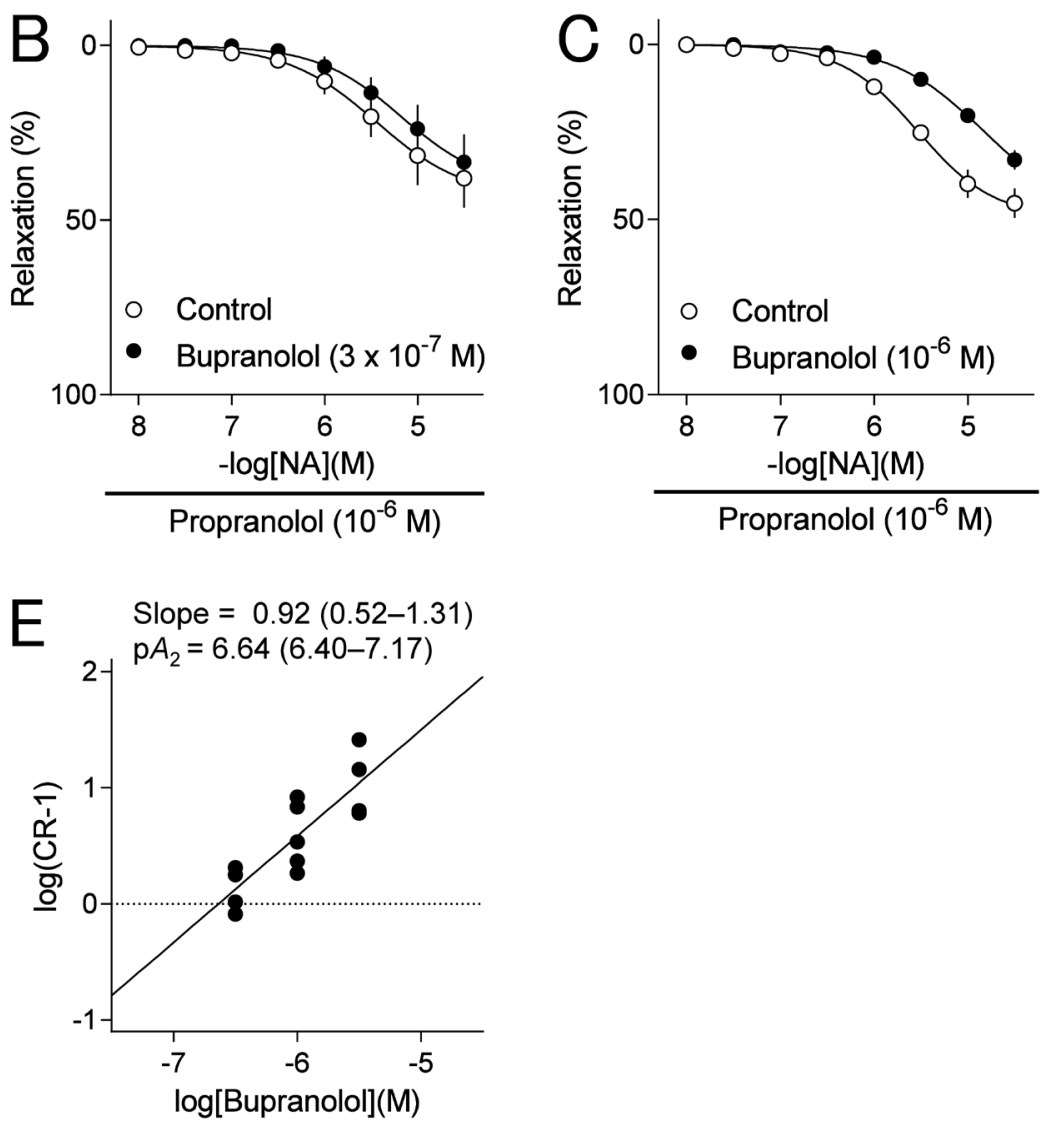

Fig. 3. Effect of Bupranolol on Noradrenaline-Induced Relaxation in Rat Urinary Bladder Smooth Muscle (UBSM)

A: Reproducibility between successive applications of the concentration-response curves for noradrenaline-induced relaxation in the presence of propranolol (10 $\left.{ }^{-6} \mathrm{M}\right)$. B-D: Effects of bupranolol $\left(3 \times 10^{-7}-3 \times 10^{-6} \mathrm{M}\right)$ on the concentration-response curves for noradrenaline-induced relaxation in the presence of propranolol $\left(10^{-6} \mathrm{M}\right)$. E: Schild plot of the bupranolol versus noradrenaline analyses shown in B-D. Data are presented as means \pm S.E.M., $n=12$ (part A), $n=5$ (part C), and $n=4$ (B, D, E). Slope and $\mathrm{p} A_{2}$ values (part E) are presented as means with $95 \%$ confidence intervals (95\% CIs).

inhibited by selective antagonists for each subtype (i.e., metoprolol for $\beta_{1}$, butoxamine or ICI-118,551 for $\beta_{2}$, and SR 59230A for $\left.\beta_{3}\right){ }^{16-18)}$ Our biochemical results and the previous mechanical studies with chemically-synthesized $\beta$-adrenoceptor agonists suggest that all $3 \beta$-adrenoceptor subtypes $\left(\beta_{1}, \beta_{2}\right.$, and $\beta_{3}$ ) could be the potential target for noradrenaline, and thus further pharmacological studies using subtype-selective antagonists are warranted.

Next, we will discuss the participation of $\beta_{1}$ - and $\beta_{2}$ adrenoceptors in noradrenaline-induced relaxation. Noradrenaline-induced relaxation was not significantly inhibited by the following $\beta$-adrenoceptor antagonists (Fig. 2): atenolol $\left(10^{-6} \mathrm{M}\right)$, a selective $\beta_{1}$-adrenoceptor antagonist at this concentration; ICI-118,551 $\left(3 \times 10^{-8} \mathrm{M}\right)$, a selective $\beta_{2}$-adrenoceptor antagonist at this concentration; propranolol $\left(10^{-7} \mathrm{M}\right)$, a $\beta_{1^{-}}$and $\beta_{2}$-adrenoceptor antagonist at this concentration; and bupranolol $\left(10^{-7} \mathrm{M}\right)$, a $\beta_{1}$ - and $\beta_{2}$-adrenoceptor antagonist at this concentration. The $\mathrm{p} A_{2}$ values of each antagonist were previously calculated to be 7.01 (atenolol for $\beta_{1}$ ), ${ }^{19)} 8.47$ (propranolol for $\beta_{1}$ ), ${ }^{20)} 8.94$ (bupranolol for $\beta_{1}$ ), ${ }^{21)} 8.83$ (ICI-118,551 for $\beta_{2}$ ), ${ }^{22)} 8.43$ (propranolol for $\beta_{2}$ ), and 8.60 (bupranolol for $\left.\beta_{2}\right){ }^{23)}$ Therefore, if either $\beta$-adrenoceptor subtype significantly contributes to noradrenaline-induced relaxation, the relaxation response should have been inhibited to some extent by these antagonists. However, since noradrenaline-induced relaxation was not affected by any of the tested antagonists, the contributions of $\beta_{1}$ and $\beta_{2}$ to this relaxation have been excluded.
Next, we will discuss the possible participation of $\beta_{3}$ adrenoceptors in noradrenaline-induced relaxation. First, noradrenaline-induced relaxation was shown to be competitively antagonized by bupranolol $\left(3 \times 10^{-7}-3 \times 10^{-6} \mathrm{M}\right)$, with a $\mathrm{p} A_{2}$ value of 6.64 (95\% CI: 6.40-7.17) (Figs. 3B-E). This $\mathrm{p} A_{2}$ value (6.64) was deemed to be nearly identical to the values in previous reports: 6.56 against BRL37344-induced relaxation in isolated ileal longitudinal smooth muscle from guinea pigs, ${ }^{12)}$ and 6.70 against CGP 12,177-induced lipolysis in white fat cells from rats. ${ }^{24)}$ Second, noradrenaline-induced relaxation was shown to be competitively antagonized by SR 59230A $\left(10^{-7}-10^{-6} \mathrm{M}\right)$, with a $\mathrm{p} A_{2}$ value of 7.27 (95\% CI: 6.92-8.38) (Fig. 4). This $\mathrm{p} A_{2}$ value (7.27) was similar to values that were previously reported: 7.58 against BRL37344-induced relaxation in isolated jejunal longitudinal smooth muscle from rabbits, ${ }^{13)}$ and 6.89 against CL 316,243-induced lipolysis in white fat cells from rats. ${ }^{24}$ These findings suggest a significant contribution of $\beta_{3}$-adrenoceptors, which are sensitive to both bupranolol and SR 59230A, to noradrenaline-induced relaxation in rat UBSM, and thus, noradrenaline could be a ligand for $\beta_{3}$-adrenoceptors in this smooth muscle.

In our study, the pharmacological detection of $\beta_{3}$ adrenoceptors with bupranolol and SR 59230A in noradrenaline-induced relaxation was carried out in the presence of $10^{-6} \mathrm{M}$ propranolol, which is similar to the conditions employed in previous reports. ${ }^{12,13)}$ In the absence of propranolol, the slope of the Schild plot regression line for bupranolol 

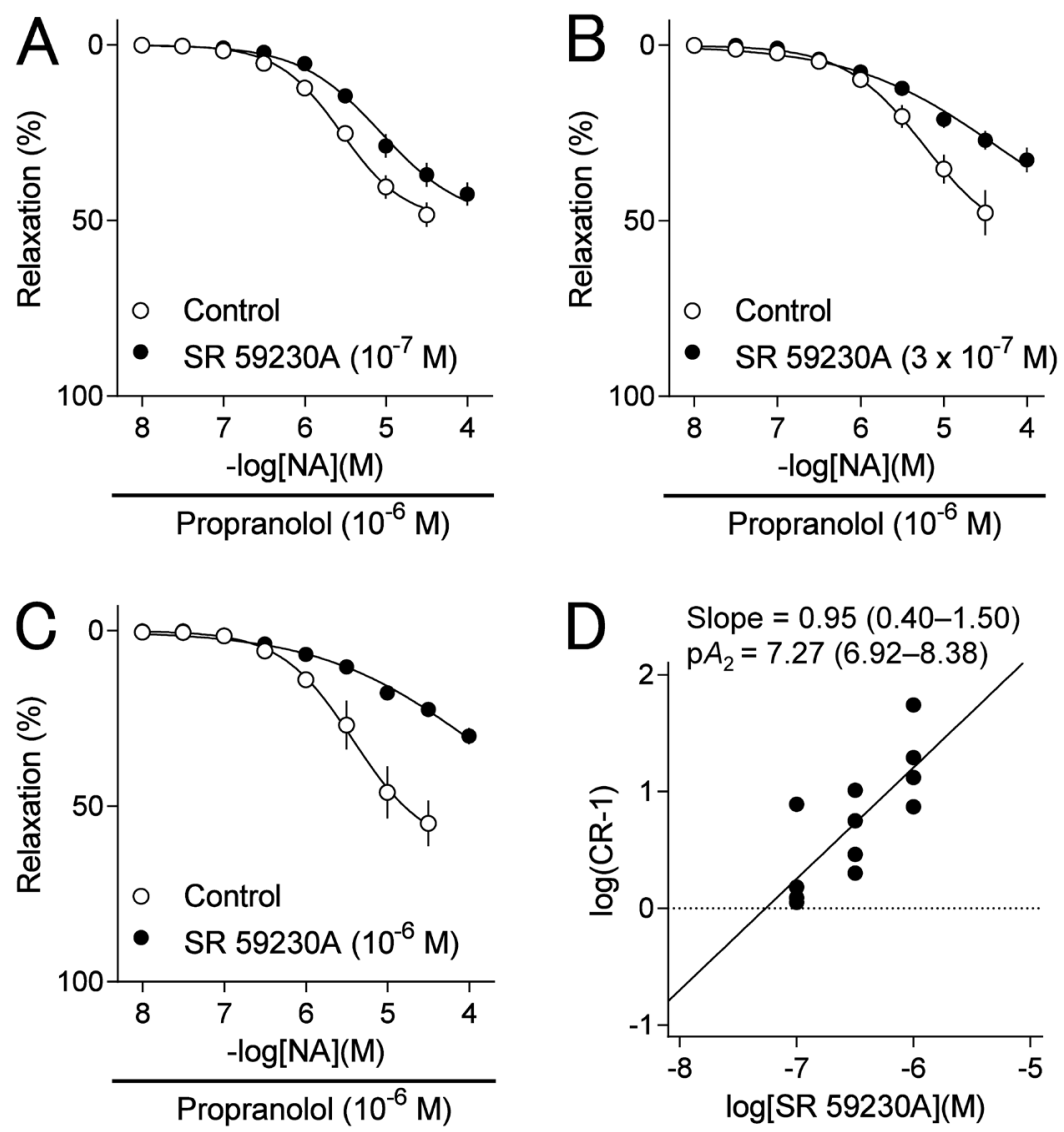

Fig. 4. Effect of SR 59230A on Noradrenaline-Induced Relaxation in Rat Urinary Bladder Smooth Muscle (UBSM)

A-C: Effects of SR 59230A $\left(10^{-7}-10^{-6} \mathrm{M}\right)$ on the concentration-response curves for noradrenaline-induced relaxation in the presence of propranolol (10 $\left.{ }^{-6} \mathrm{M}\right)$. D: Schild plot of the SR 59230A versus noradrenaline analyses shown in A-C. Data are presented as means \pm S.E.M., $n=4$. Slope and p $A_{2}$ values (part D) are presented as means with $95 \%$ confidence intervals ( $95 \%$ CIs).
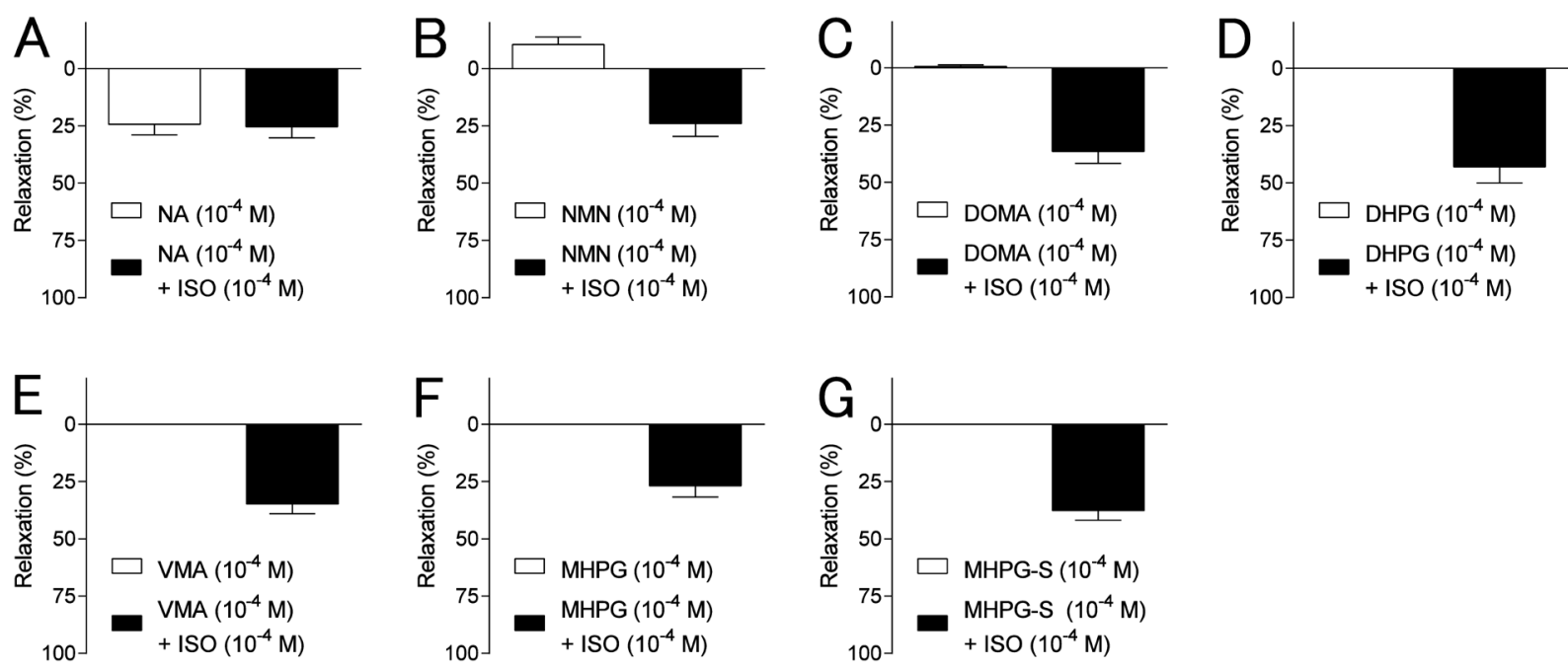

Fig. 5. Effect of Noradrenaline (A) and 6 Noradrenaline Metabolites $(B-G)$ on Methacholine $\left(3 \times 10^{-5} \mathrm{M}\right)$-Induced Contraction in Rat Urinary Bladder Smooth Muscle (UBSM) in the Presence of Clorgiline (Monoamine Oxidase A $\left(\mathrm{MAO}_{\mathrm{A}}\right)$ Inhibitor, $\left.10^{-5} \mathrm{M}\right)$ and 3,5-Dinitrocatechol $(\mathrm{Catechol}-\mathrm{O}$ methyltransferase (COMT) Inhibitor, $\left.2 \times 10^{-6} \mathrm{M}\right)$

Tested noradrenaline metabolites $\left(10^{-4} \mathrm{M}\right)$ are normetanephrine (NMN; B), 3,4-dihydroxymandelic acid (DOMA; C), 3,4-dihydroxyphenylglycol (DHPG; D), 4-hydroxy3-methoxymandelic acid (VMA; E), 4-hydroxy-3-methoxyphenyl glycol (MHPG; F), and 4-hydroxy-3-methoxyphenylglycol sulfate (MHPG-S; G). Data are presented as means \pm S.E.M., $n=4$. ISO: isoprenaline.

$\left(3 \times 10^{-7}-3 \times 10^{-6} \mathrm{M}\right)$ against noradrenaline was far less than unity; thus, we could not calculate the $\mathrm{p} \mathrm{A}_{2}$ value for bupranolol, necessitating the inclusion of $10^{-6} \mathrm{M}$ propranolol (data not shown).
In rat UBSM, all three $\beta$-adrenoceptors have been shown to be functional, ${ }^{16-18)}$ and bupranolol was reported to competitively inhibit isoprenaline-induced relaxation with a $\mathrm{p} A_{2}$ value of $8.98 .^{25)}$ This corresponds to the value for $\beta_{1}$ or $\beta_{2}{ }^{21,23)}$ 
but not to that for $\beta_{3}$. Therefore, since bupranolol binds nonselectively to all 3 subtypes $\left(\beta_{1}, \beta_{2}\right.$, and $\left.\beta_{3}\right)$ in rat UBSM and noradrenaline binds selectively to the $\beta_{3}$-adrenoceptor, competitive antagonism of bupranolol against noradrenaline would not be expected to occur in the absence of propranolol to block $\beta_{1}$ and $\beta_{2}$. In contrast, in the presence of propranolol $\left(10^{-6} \mathrm{M}\right)$, both $\beta_{1}$ and $\beta_{2}$ are occupied by propranolol, which enables bupranolol to selectively bind to $\beta_{3}$ and competitively antagonize noradrenaline. Thus, the slope of the Schild plot regression line for bupranolol versus noradrenaline becomes unity, which enables the $\mathrm{p} A_{2}$ value to be calculated.

However, propranolol at $10^{-6} \mathrm{M}$ shifted the concentrationresponse curve for noradrenaline-induced relaxation to the right by $c a$. 2-fold (Fig. 2E). This finding is consistent with previous reports that the $\mathrm{p} A_{2}$ value of propranolol for the $\beta_{3}$ adrenoceptor is approximately $6 .^{26,27)}$ Therefore, it is possible that this concentration $\left(10^{-6} \mathrm{M}\right)$ of propranolol is able to inhibit $\beta_{3}$-adrenoceptors to some extent in addition to inhibiting $\beta_{1}$ and $\beta_{2}$, although a control experiment was also performed in the presence of propranolol $\left(10^{-6} \mathrm{M}\right)$ and the $\mathrm{p} A_{2}$ values for bupranolol and SR 59230A were almost identical to the previously reported values. ${ }^{26,27)}$

Finally, we will discuss the results of the noradrenaline metabolites. There were several reasons why we chose to examine their effects. Noradrenaline had been suggested to be an agonist for $\beta_{3}$-adrenoceptors by pharmacological functional studies, and thus, its metabolites could also be $\beta_{3^{-}}$adrenoceptor agonists. In addition, since noradrenaline metabolites can be discharged into the urine, it is possible that they relax the bladder by stimulating internal UBSM or urothelium $\beta_{3}$-adrenoceptors to promote urine storage. Previously, NMN, a metabolite of noradrenaline, was shown to have positive inotropic actions in guinea pig atrial muscle, ${ }^{28)}$ and $\mathrm{MHPG}$, another metabolite of noradrenaline, was shown to inhibit lymphocyte chemotaxis similarly to the action of noradrenaline. ${ }^{29)}$ However, none of the six noradrenaline metabolites (i.e., NMN, DOMA, DHPG, VMA, MHPG, and MHPG-S) showed relaxation responses in our study (Fig. 5). Therefore, these metabolites are unlikely endogenous agonists of the $\beta_{3^{-}}$adrenoceptor in rat UBSM; the endogenous agonist is most likely noradrenaline itself. Although NMN stimulated contraction instead of relaxation, we currently do not understand this phenomenon, which should be examined in future studies.

\section{CONCLUSION}

Noradrenaline, but not its metabolites, may be a ligand for $\beta_{3}$-adrenoceptors to produce relaxation responses in the UBSM of rats. However, our present study was performed with exogenously applied, and not endogenous, noradrenaline. Therefore, further studies are required to examine whether $\beta_{3}$ adrenoceptors are targets for endogenous noradrenaline.

Acknowledgments This work was partly supported by The Research Grants of Toho University Faculty of Pharmaceutical Sciences.

Conflict of Interest The authors declare no conflict of interest.

\section{REFERENCES}

1) Bortolini MA, Bilhar AP, Castro RA. Neural control of lower urinary tract and targets for pharmacological therapy. Int. Urogynecol. J., 25, 1453-1462 (2014).

2) de Groat WC, Griffiths D, Yoshimura N. Neural control of the lower urinary tract. Compr. Physiol., 5, 327-396 (2015).

3) Shah AP, Mevcha A, Wilby D, Alatsatianos A, Hardman JC, Jacques S, Wilton JC. Continence and micturition: an anatomical basis. Clin. Anat., 27, 1275-1283 (2014).

4) Wallukat $\mathrm{G}$. The $\beta$-adrenergic receptors. Herz, 27, 683-690 (2002).

5) Yamaguchi O, Chapple CR. $\beta_{3}$-Adrenoceptors in urinary bladder. Neurourol. Urodyn., 26, 752-756 (2007).

6) Nomiya M, Yamaguchi O. A quantitative analysis of mRNA expression of $\alpha 1$ and $\beta$-adrenoceptor subtypes and their functional roles in human normal and obstructed bladders. J. Urol., 170, 649-653 (2003).

7) Chapple CR, Cardozo L, Nitti VW, Siddiqui E, Michel MC. Mirabegron in overactive bladder: a review of efficacy, safety, and tolerability. Neurourol. Urodyn., 33, 17-30 (2014).

8) Takasu T, Ukai M, Sato S, Matsui T, Nagase I, Maruyama T, Sasamata M, Miyata K, Uchida H, Yamaguchi O. Effect of $(R)-2$ (2-aminothiazol-4-yl)-4'-\{2-[(2-hydroxy-2-phenylethyl)amino]ethyl $\}$ acetanilide (YM178), a novel selective $\beta_{3}$-adrenoceptor agonist, on bladder function. J. Pharmacol. Exp. Ther., 321, 642-647 (2007).

9) Wu T, Duan X, Cao CX, Peng CD, Bu SY, Wang KJ. The role of mirabegron in overactive bladder: a systematic review and metaanalysis. Urol. Int., 93, 326-337 (2014).

10) Seguchi H, Nishimura J, Zhou Y, Niiro N, Kumazawa J, Kanaide H. Expression of $\beta 3$-adrenoceptors in rat detrusor smooth muscle. $J$. Urol., 159, 2197-2201 (1998).

11) Fujimura $T$, Tamura $K$, Tsutsumi $T$, Yamamoto $T$, Nakamura $K$, Koibuchi Y, Kobayashi M, Yamaguchi O. Expression and possible functional role of the $\beta 3$-adrenoceptor in human and rat detrusor muscle. J. Urol., 161, 680-685 (1999).

12) Horinouchi $T$, Koike K. Functional identification of $\beta_{3}$ adrenoceptors in the guinea-pig ileum using the non-selective $\beta$-adrenoceptor antagonist ( \pm )-bupranolol. J. Auton. Pharmacol., 20, 253-258 (2000)

13) MacDonald A, Watt K. Characterisation of the atypical $\beta$-adrenoceptor in rabbit isolated jejunum using BRL 37344, cyanopindolol and SR 59230A. J. Auton. Pharmacol., 19, 91-95 (1999).

14) Arunlakshana O, Schild HO. Some quantitative uses of drug antagonists. Br. J. Pharmacol. Chemother., 14, 48-58 (1959).

15) Eisenhofer G, Finberg JP. Different metabolism of norepinephrine and epinephrine by catechol- $O$-methyltransferase and monoamine oxidase in rats. J. Pharmacol. Exp. Ther., 268, 1242-1251 (1994).

16) Longhurst PA, Levendusky $M$. Pharmacological characterization of $\beta$-adrenoceptors mediating relaxation of the rat urinary bladder in vitro. Br. J. Pharmacol., 127, 1744-1750 (1999).

17) Granato C, Korstanje C, Guilloteau V, Rouget C, Palea S, Gillespie JI. Prostaglandin $\mathrm{E}_{2}$ excitatory effects on rat urinary bladder: a comparison between the $\beta$-adrenoceptor modulation of non-voiding activity in vivo and micro-contractile activity in vitro. Naunyn Schmiedebergs Arch. Pharmacol., 388, 727-735 (2015).

18) Oshita M, Hiraoka Y, Watanabe Y. Characterization of beta-adrenoceptors in urinary bladder: comparison between rat and rabbit. $\mathrm{Br}$. J. Pharmacol., 122, 1720-1724 (1997).

19) Tanaka Y, Shinoda K, Sekiya S, Yamaki F, Shibano M, Yamashita Y, Horinouchi T, Koike K. $\beta_{1}$-Adrenoceptor-mediated relaxation with isoprenaline and the role of MaxiK channels in guinea-pig esophageal smooth muscle. J. Smooth Muscle Res., 40, 43-52 (2004).

20) Horinouchi T, Tanaka $Y$, Koike K. Function of $\beta_{1}$-adrenoceptors and mRNA expression of $\beta_{1}$ - and $\beta_{2}$-adrenoceptors in guinea-pig esophagus. Eur. J. Pharmacol., 473, 79-82 (2003).

21) Tanaka Y, Yamashita Y, Michikawa H, Horinouchi T, Koike K. 
Pharmacological characterization of the $\beta$-adrenoceptor that mediates the relaxant response to noradrenaline in guinea-pig tracheal smooth muscle. Naunyn Schmiedebergs Arch. Pharmacol., 375, 51-64 (2007).

22) Tanaka Y, Yamashita Y, Horinouchi T, Yamaki F, Koike K. Evidence showing that $\beta$-adrenoceptor subtype responsible for the relaxation induced by isoprenaline is principally $\beta_{2}$ but not $\beta_{1}$ in guinea-pig tracheal smooth muscle. Auton. Autacoid Pharmacol., 24, 37-43 (2004)

23) Koike K, Ichino T, Horinouchi T, Takayanagi I. The $\beta_{2}$ - and $\beta_{3}$ adrenoceptor-mediated relaxation induced by isoprenaline and salbutamol in guinea pig taenia caecum. J. Smooth Muscle Res., 33, 99-106 (1997).

24) Galitzky J, Langin D, Verwaerde P, Montastruc JL, Lafontan M, Berlan M. Lipolytic effects of conventional $\beta_{3}$-adrenoceptor agonists and of CGP 12,177 in rat and human fat cells: preliminary pharmacological evidence for a putative $\beta_{4}$-adrenoceptor. $B r . J$. Pharmacol., 122, 1244-1250 (1997).
25) Yamazaki $Y$, Takeda H, Akahane M, Igawa $Y$, Nishizawa O, Ajisawa Y. Species differences in the distribution of $\beta$-adrenoceptor subtypes in bladder smooth muscle. Br. J. Pharmacol., 124, 593-599 (1998).

26) Tanaka E, Yamakawa A, Yamamura M, el Borai N, Ito K, Nakano S, Nakazawa H. Regulation of heat production of brown adipocytes via typical and atypical $\beta$-adrenoceptors in the rat. Jpn. J. Physiol., 45, 1043-1051 (1995).

27) Van Liefde I, Van Witzenburg A, Vauquelin G. Multiple beta adrenergic receptor subclasses mediate the $l$-isoproterenol-induced lipolytic response in rat adipocytes. J. Pharmacol. Exp. Ther., 262, 552-558 (1992)

28) Langer SZ, Rubio MC. Effects of the noradrenaline metabolites on the adrenergic receptors. Naunyn Schmiedebergs Arch. Pharmacol., 276, 71-88 (1973).

29) García JJ, del Carmen Sáez M, De la Fuente M, Ortega E. Noradrenaline and its end metabolite 3-methoxy-4-hydroxyphenylglycol inhibit lymphocyte chemotaxis: role of alpha- and beta-adrenoreceptors. Mol. Cell. Biochem., 254, 305-309 (2003). 